\title{
35. MANGANESE DEPOSITS ENCOUNTERED DURING DEEP SEA DRILLING PROJECT, LEG 29, IN SUBANTARCTIC WATERS
}

\author{
Stanley V. Margolis, Department of Oceanography, Hawaii Institute \\ of Geophysics, University of Hawaii, Honolulu, Hawaii
}

\begin{abstract}
Manganese nodules, micronodules, and crusts were encountered in surface sediments, and at depth, in 6 of the 10 sites drilled during DSDP Leg 29 south of New Zealand and Tasmania. Major concentrations of surface nodule pavements occur on and adjacent to the Campbell Plateau south of New Zealand, south of the Tasman Rise, and in the South Tasman Sea. These deposits are found on top of erosional unconformities, which span tens of millions of years and reflect scouring by strong bottom currents. Micronodules were also found at depth throughout most of these cores. Their occurrence apparently is dependent upon a number of environmental factors.
\end{abstract}

\section{INTRODUCTION}

Sediment cores recovered during DSDP Leg 29 in the Subantarctic afforded the opportunity to investigate the occurrence of deep-sea manganese deposits in sediments spanning the past 100 million years. The regions covered by Leg 29 (Figure 1) represent a variety of different oceanographic, climatic, bathymetric, and tectonic regimes. The purpose of this study was to determine the distribution of manganese nodules, micronodules, and crusts in surface sediments and at depth in the cores collected on this cruise.

Large manganese nodules, found at depth in cores, were checked to determine if they are indeed in situ, or represent downhole contamination. Smaller nodules and micronodules, which were in place, were sampled. Their morphology and occurrence were noted according to sediment type, and sedimentary structures. The relative abundance of micronodules and pellets was determined by point counting from the $>62 \mu$ washed fraction. These data were compared with variations in biogenic, detrital, and authigenic sediment components.

\section{RESULTS}

\section{Site 275 (Southeastern edge of Campbell Plateau; water} depth 2800 m)

A thin Pleistocene veneer of foraminiferal ooze, containing manganese nodules and crusts, overlies siliceous sediments of Late Cretaceous age. The nodules (Plate 1) are black to gray, between $3-6 \mathrm{~cm}$ in diameter, rounded to elliptical, and frequently contain phosphatic patches. Those nodules found in the Upper Cretaceous sediments contain Quaternary foraminifera in recessed portions, indicating that they were dragged down from the present sea floor during drilling. The manganese nodule pavement and unconformity apparently cover a large portion of the Southern Campbell Plateau (Summerhayes, 1969) and indicate the presence and development of a strong western boundary current even at these depths. The nuclei on nodules found at this site frequently consist of indurated carbonate and phosphatic rock, eroded from elsewhere $o$ the plateau. The origin of these manganese deposits may be similar to the origin of those on the Blake Plateau off the southeastern United States.

Chemical analysis of three of these nodules with an EDAX X-ray flourescence unit indicates relatively high $\mathrm{Ca}, \mathrm{F}$, and $\mathrm{P}$, apparently from the flouropatite present. The nodules were also relatively rich in $\mathrm{Ti}, \mathrm{K}, \mathrm{Si}, \mathrm{Mg}$, and $\mathrm{Al}$, probably in the form of included clay minerals. Manganese concentrations were about four times greater than that of iron, and no significant amounts of $\mathrm{Ni}, \mathrm{Cu}$, and $\mathrm{Co}$ were detected.

Site 276 (Beyond the edge of Campbell Plateau; water depth $\mathbf{4 6 7 0} \mathbf{~ m}$ )

No core recovery was obtained at this site. However, scrapings from the bit and core catcher contained detrital mineral grains coated with manganese and iron, and granules, platelets, micronodules, and fragments of larger manganese nodules. This indicated the presence of a surficial lag deposit of sandy gravel and manganese, caused by winnowing and erosion by a western boundary current.

\section{Site 278 (Southern Emerald Basin; water depth $\mathbf{3 6 7 5}$ m)}

Micromanganese nodules were found throughout the sediments at this site. The manganese commonly occurs as a replacement of foraminifera tests (Plate 2; Figures $1,2,3,4)$ and also growing epitaxically on siliceous microfossils (Plate 2; Figures 5, 6). Microprobe analysis indicates that these micronodules are fairly pure manganese oxide, with little or no $\mathrm{Co}, \mathrm{Fe}$, or $\mathrm{Ni}$. Dissolution of planktonic tests, therefore, may play an important role in serving as nuclei for manganese precipitation, either while falling through the water column or while on the sea floor. Decomposition of organic material, either in tests or in fecal pellets (Plate 


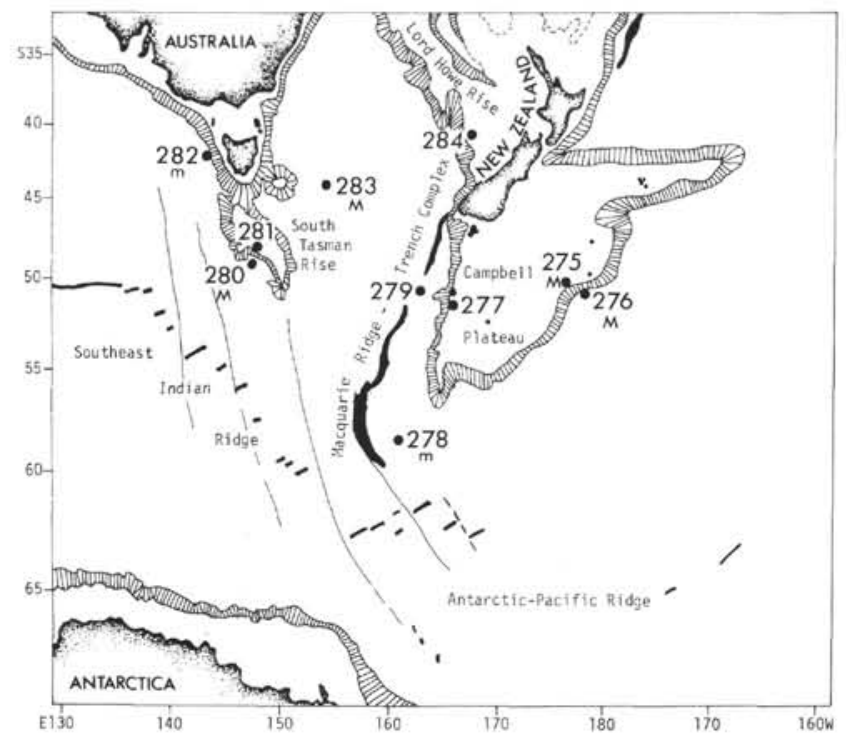

Figure 1. Map showing sites drilled during DSDP Leg 29. Upper-case " $M$ " next to site indicates that manganese nodules and pavements were encountered in surface sediments and that micronodules were distributed throughout the deeper cores in older sediment. Lower case " $m$ " indicates that micronodules were found throughout deeper cores, but no nodules or pavements were found in surface sediments. Studies of this nature on the paleoenvironments of manganese nodule accretion will enable us to understand the physical and chemical conditions controlling manganese distribution in the oceans. The occurrence of manganese at depth in cores might indicate if there is any vertical movement of manganese ions in the sediment column beneath surface deposits.

1), may also influence manganese precipitation. In addition, no physical evidence was found for manganese solution at depth. Indeed, some of the highest concentrations of micronodules were found in the oldest (Eocene) sediments, which are characterized by low sedimentation rates, and which were deposited prior to the development of the Antarctic convergence (middle Cenozoic), and its associated high biological productivity.

The following accompanied relative increases in the abundance of manganese micronodules and pellets at Site 278: (a) decreased or lower rates of sedimentation, (b) increased amounts of volcanogenic sediment, (c) increased evidence for winnowing by bottom currents, (d) increased amounts of ice-rafted sediments from Antarctica, and (e) decreased amounts of pyrite, glauconite, chert, and terrigenous sediments.

\section{Site 280 (South of the South Tasman Rise; water depth $4176 \mathrm{~m}$ )}

Large black-brown manganese and phosphate nodules (Plate 3 ) occur sporadically in the top 1 meter of the late Pleistocene foraminifera and diatom-bearing nannofossil ooze, and also at the top of deeper cores as drilling contaminants, similar to those at Site 275. Their abundance indicates that a manganese nodule pavement covers the sea floor in this region. Analysis of two nodules from this site indicates appreciable silica, both in the form of clay minerals and as siliceous tests; calcium mainly as foraminifera and coccolith tests; and $\mathrm{Ti}$ from clay minerals. The differences between these nodules and those from Site 275 are that they contain about twice as much manganese as iron and also contain detectable $(>1.0 \%) \mathrm{Ni}$ and $\mathrm{Cu}$, and therefore are of greater economic interest.

Beneath the thin veneer of late Pleistocene sediments is another thin sequence of early Pleistocene, or late Miocene, siliceous clay on top of a large unconformity developed on mid-to-late Oligocene siliceous ooze and Eocene silt. There is a general decrease in the abundance of micromanganese nodules with depth at this site, and a corresponding increase in glauconite and organic carbonaceous material. The transition from reducing to oxidizing conditions may be caused by the separation of Australia from Antarctica and the removal of the circulation barrier created by the South Tasman Rise. Upward increase in manganese deposits reflects increased tempo of circumpolar circulation.

\section{Site 283 (South Tasman Sea; water depth 4729 m)}

Soft botryoidal, brown manganese nodules were recovered in Sample 1, CC at Site 283 (Hole 283A). They are associated with micronodule-rich zeolitic silt and clay of Pleistocene (?) age. Much of the Cenozoic is missing beneath this. The next sediments encountered were diatom oozes of late Eocene age. The micronodule content for the remaining sequence is variable but increases with slight increases in fine volcanic glass content.

The presence of a manganese nodule pavement in the South Tasman Sea has been documented by previous workers in this area (Watkins and Kennett, 1973).

\section{CONCLUSIONS}

Manganese nodules and pavements in the Southern Ocean rest on vast regional unconformities in the sediment record, in areas extensively scoured by strong bottom currents.

The increased tempo in circumpolar circulation, associated with the increased Antarctic glaciation during the late Cenozoic, may be responsible for these regional unconformities and the manganese nodule pavements developed on them. The lack of any buried manganese nodule pavements at depth in the drill cores from this region possibly indicates that the development of extensive nodule deposits on the ocean floor is a feature unique to the late Cenozoic. It may be the result of increased oceanic circulation, production, and movement of oxygenated Antarctic bottom waters (AABW), caused by extensive Antarctic glaciation. Since AABW spreads north of the equator in the Pacific and locally produces scour around bottom structures and high biological productivity in regions of upwelling, its 
movements and hydrographic properties should be charted relative to the distribution of rich manganese nodule deposits (Margolis and Glasby, 1973).

Many micronodules of manganese are formed by progressive dissolution of siliceous and calcareous microfossils and concurrent epitaxic growth of manganese microcrystals. It is not known if this process occurs: (a) in the seawater column, (b) on the seafloor; or (c) after burial. No evidence was found for dissolution of micronodules after burial. Differentiation of iron (hydrotriolite, hematite, pyrite) micronodules, and manganese micronodules by optical techniques proved to be often misleading. However, energy-dispersive (EDAX) methods used in conjunction with an SEM is the best method of identifying these components.

Preliminary results indicate interesting trends when comparing increases in the abundance of manganese with increases in volcanic sediments, ice-rafted debris, and winnowing, and with decreases in sedimentation rate, pyrite, glauconite, chert, and terrigenous sediments.

\section{ACKNOWLEDGMENTS}

This work was made possible by grants from the National Science Foundation to support the Deep Sea Drilling Project, contracted to Scripps Institute of Oceanography, and to the Hawaii Institute of Geophysics for the purchase of the Scanning Electron Microscope Laboratory, and by support from the International Decade of Ocean Exploration for the Interuniversity Ferromanganese Program.

\section{REFERENCES}

Margolis, S. and Glasby, G., 1973. Microlaminations in marine manganese nodules as revealed by scanning electron microscopy: Geol. Soc. Am. Bull., v. 84, p. 3601-3610.

Summerhayes, C., 1969. Marine geology of the New Zealand Subantarctic seafloor: New Zealand Ocean. Inst., Memo. No. 50,92 p.

Watkins, N. and Kennett, J. P., 1972. Regional sedimentary disconformities and upper Cenozoic changes in bottom water velocities between Australasia and Antarctica, In Antarctic Oceanology II: The Australian-New Zealand Sector. Antarctic Res. Ser., v. 19, p. 269-93. 


\section{PLATE 1}

Reflecting light micrographs of polished sections of manganese nodules from Leg 29.

Figure 1 Dark brown nodule from Site 280. Note welldeveloped concentric laminations. Nucleus consists of sandstone fragment containing glauconite and pyrite. Magnification: $4 \times$.

Figure 2 Light brown spherical nodule from Site 280 with chert nucleus and manganese dendrites. Outer portion of nodule was eroded, but this may have happened during recovery. Magnification: $3 \times$.

Figure 3 Elliptical nodule from Site 275, consisting of manganese and phosphate. Note asymmetrical shape and lack of well-developed laminations. Magnifications: $4 \times$. 
PLATE 1
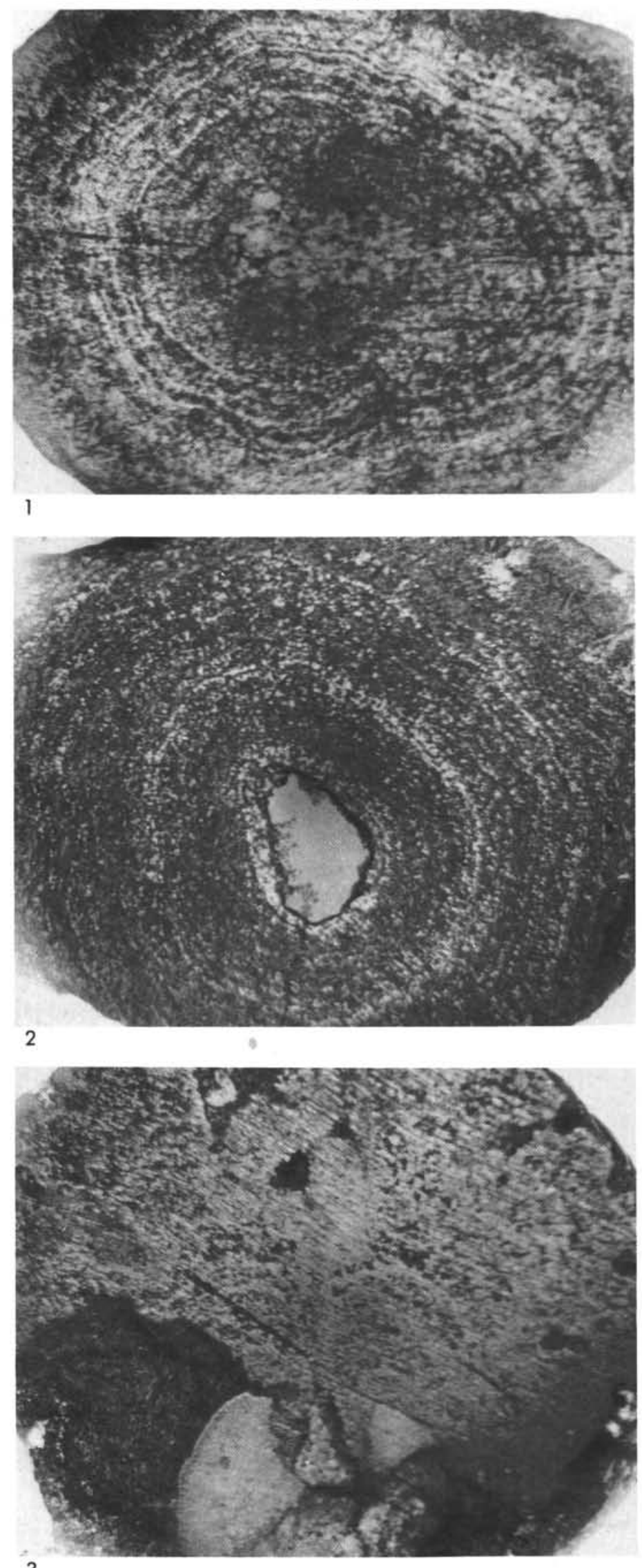


\section{PLATE 2}

All photos are scanning electron micrographs of manganese encountered at Site 278 from DSDP Leg 29. Manganese micronodules and aggregates were found in sediments of Pleistocene through Oligocene age.

Figure $1 \quad$ A fractured aggregate of manganese pellets which indicates that it was formed by replacement of a planktonic foraminifera test. Energy dispersive Xray analysis indicated that no calcium was present, just manganese and a trace of iron.

Figure 2 Lower magnification photo of an aggregate similar to Figure 1, however, this one is unfractured. Masses similar to this are quite common in deep-sea sediments.

Figures 3, 4 Progressively higher magnification photos of the thin sheet-like crystals of manganese as indicated by the EDAX, found on the surface of pellets, aggregates, micro and macro nodules of manganese in deep-sea cores. Similar crystals are also found on present-day ocean floor manganese deposits. No evidence of dissolution is apparent. Electron diffraction will be necessary to identify the exact mineralogy of such crystals.

Figure 5 A diatom from Site 278 which has crystals identified as being manganese-rich growing on the surface. All stages of diatom dissolution and replacement by manganese were noted.

Figure $6 \quad$ High magnification photo of manganese crystal cluster shown in Figure 5. The crystals were indicated by the EDAX to be identical in composition to those shown in Figures 4, 5. Electron diffraction studies of such crystals differing in morphology are essential to their mineral identification. 
PLATE 2

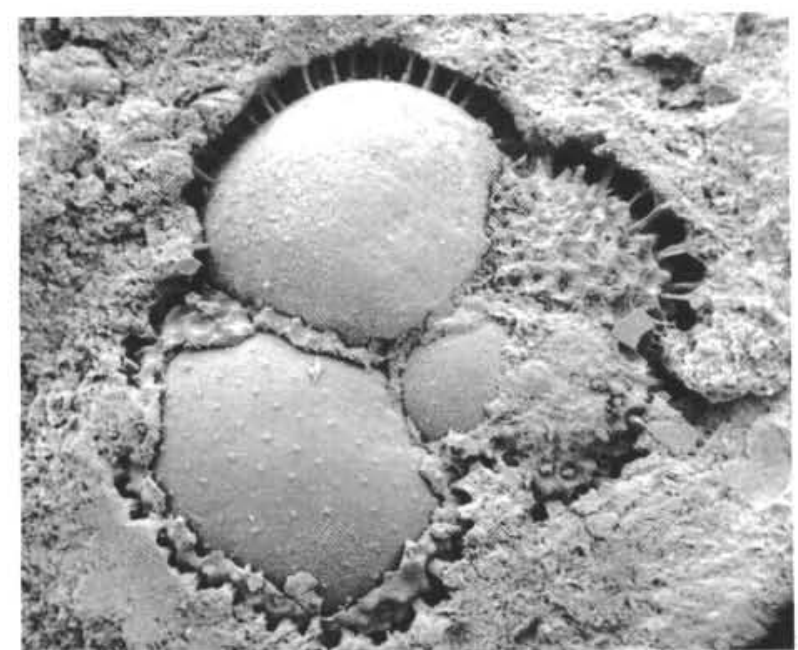

$80 \mu$

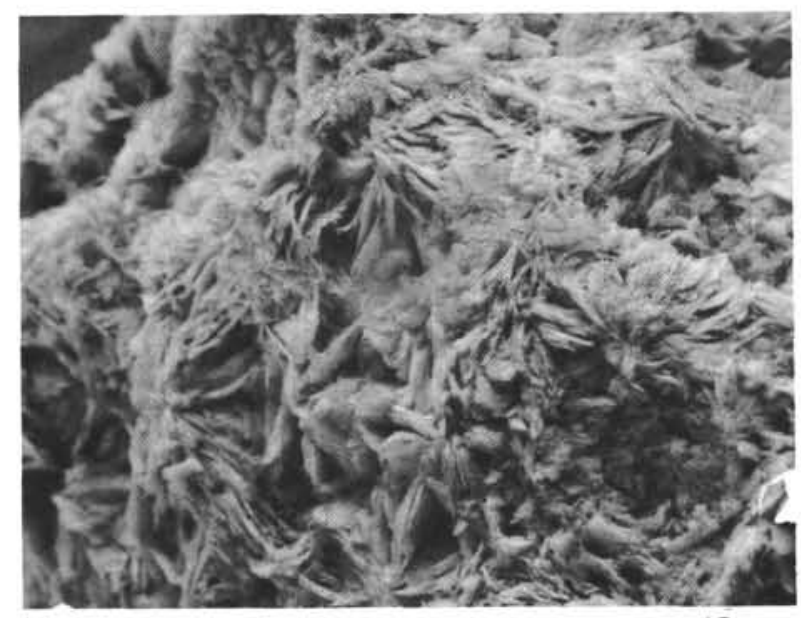

3

$45 \mu$

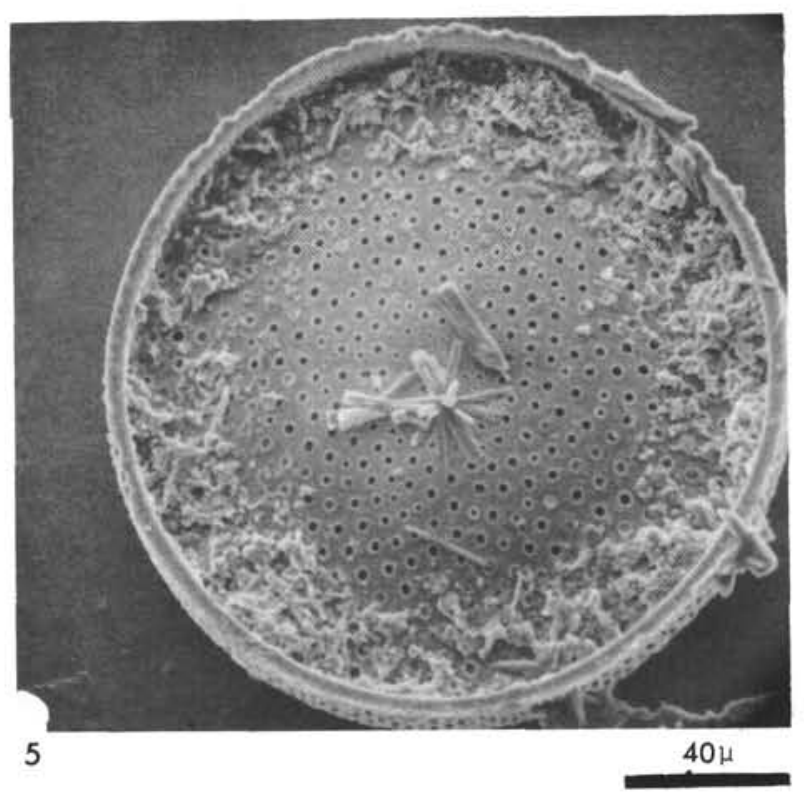

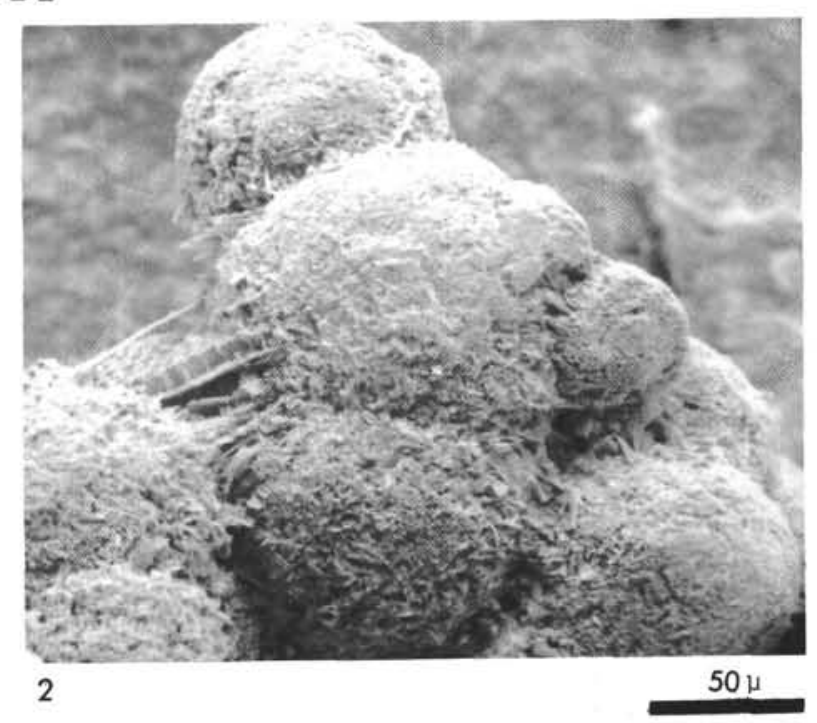
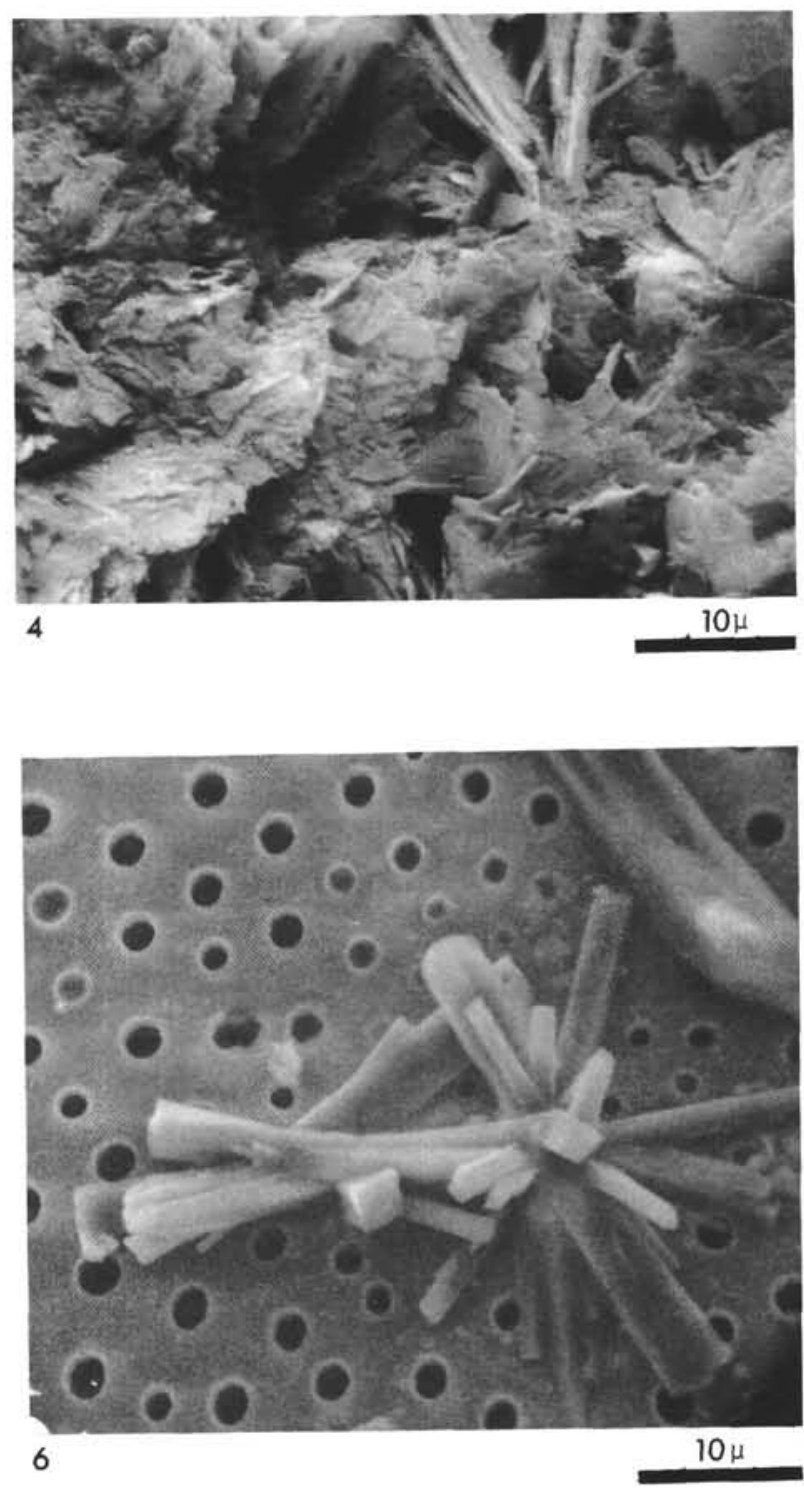


\section{PLATE 3}

All photos are SEM micrographs of micromanganese pellets from Site 278.

Figure 1 Small bryozoan or coral fragment, replaced by manganese.

Figure 2 Round fecal pellet consisting of small round blebs of manganese.

Figure 3 Thin worm (?) tube lined with manganese crystals.

Figure $4 \quad$ Higher magnification photo of Figure 3 showing details of crystal structure.

Figure 5 Thin smooth tube replaced by manganese.

Figure $6 \quad$ Higher magnification photo of figure 5 showing crystal outlines. 
PLATE 3
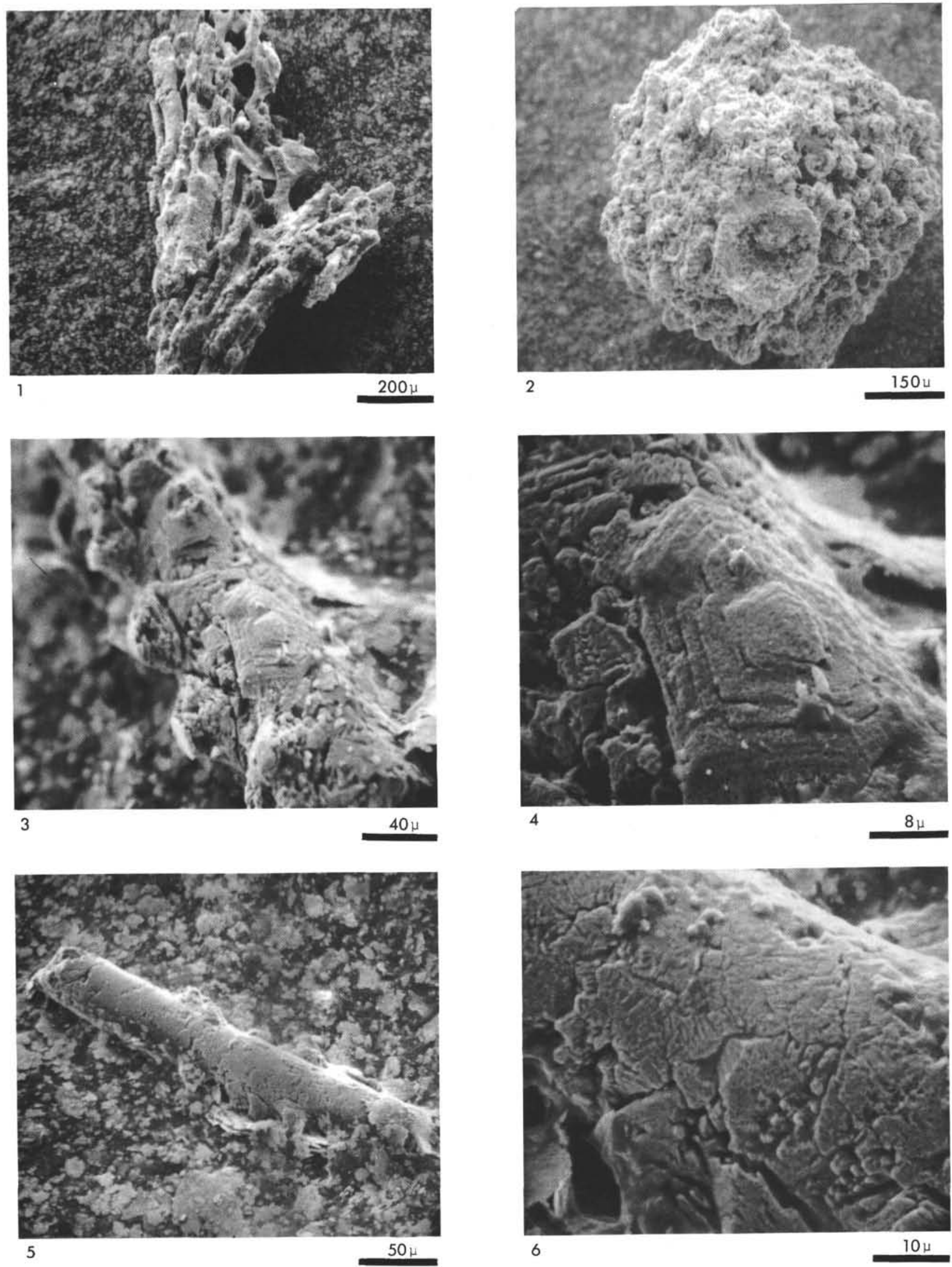